\title{
Mirar en la contemplación de una provocación estética. A propósito de la obra de Tulio Restrepo*
}

Hilderman Cardona-Rodas

Universidad de Medellín, Medellín, Colombia

hcardona@udem.edu.co

https://orcid.org/0000-0002-6778-2102

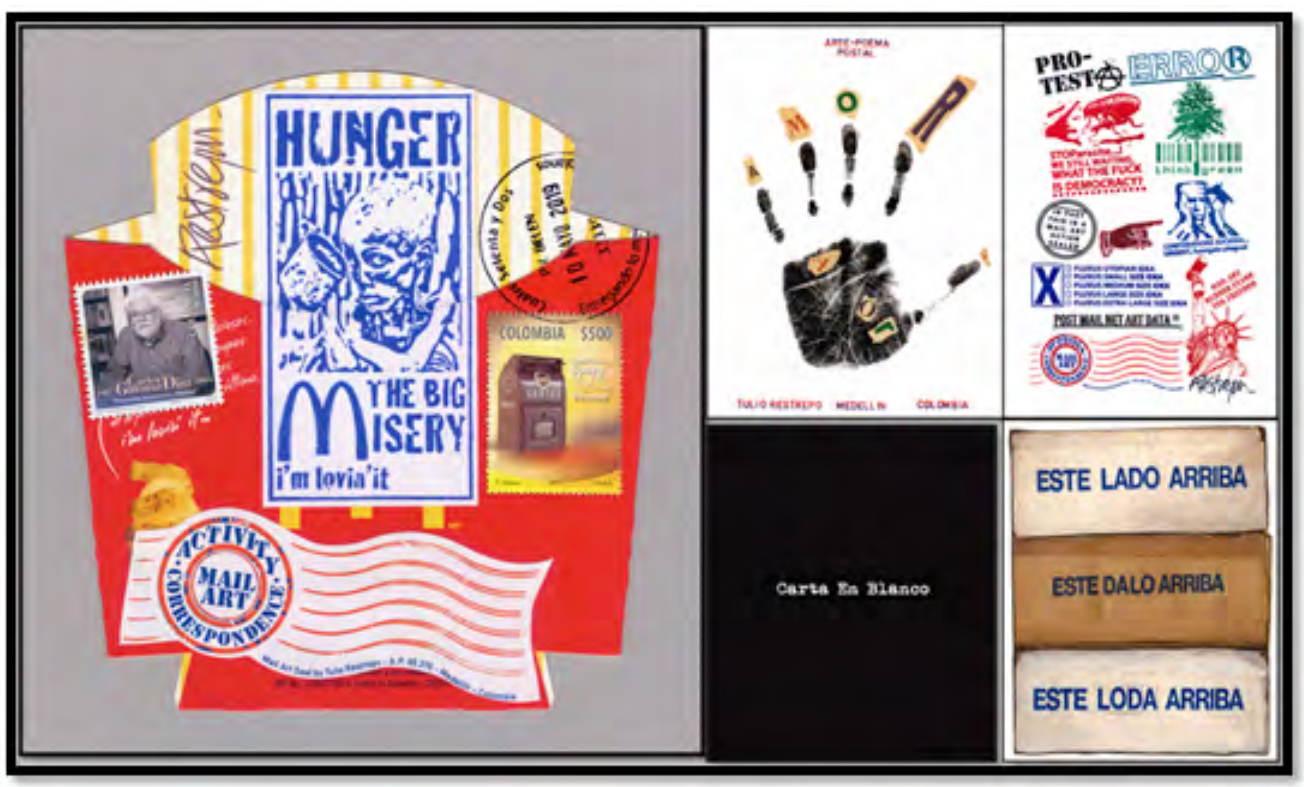

Selección de obras de Tulio Restrepo presentes en este número de la revista

Fuente: Restrepo (2019).

Cómo citar: Cardona-Rodas, H. (2020). Mirar en la contemplación de una provocación estética. A propósito de la obra de Tulio Restrepo. Ciencias Sociales y Educación, 9(17), 379-384. https://doi.org/10.22395/csye.v9n17a21 Recibido: 15 de enero de 2020.

Aprobado: 25 de febrero de 2020. 
Tulio Restrepo ofrenda el espacio crítico de la violencia visual de los ídolos contemporáneos. En su obra, el espacio en blanco es la archihuella de una sospecha: aquello que vemos se hace materia cuando comprendemos que, al mirar una imagen hoy, se hace en términos de mercancía. Marca e inscritura conversan en la materialidad afectante de una topología analítica que muestra nuestro presente contradictorio. Sellos, mercancías, huellas, empaquetados o espacios en blancos muestran una memoria de la escritura de la diferencia (Derrida, 1971). Esa diferencia es el vínculo recíproco del acto performático de la lectura, pues la obra deviene lector cuando este encuentra el sentido de la trama imbricada en la imagen. Una crítica gramatológica gravita en la obra de Tulio Restrepo, pues la imagen es el dispositivo analítico para hacer de lo visible el espacio estético de la crítica. Hunger the big misery, El amor en sus manos, Carta en blanco, Sellos de Artista Correo, De lado y Desaparecido, obras elegidas para integrar la propuesta estética de la revista Ciencias Sociales y Educación, 9(17), despliegan la crítica de un artista-maestro que en las intensidades enigmáticas del arte abre un panorama para comprender lo que es visible en la ausencia de la interpretación. Aquí la obra es una inscriptura que solo puede ser comprendida cuando aquello que se ve se hace affectus en la maquina deseante de lo que quiere ser expresado.

Sellar o dejar huella se hace experiencia si se tiene algo que decir. Efectivamente, en Tulio Restrepo la obra es una huella tipográfica que disuelve, a pesar de él, la presencia del lenguaje encarnado en la imagen. Su obra explora los matices y puntos de fuga de los movimientos artísticos de la segunda mitad del siglo XX denominados mail art y fluxus que, con relación a lo planteado en esta reseña, pone en juego una hibridación estética de varias prácticas artísticas que tiene, en las exploraciones entre sonido e imagen del norteamericano John Cage (1912-1992), su expresión en flujo comprensivo. En sus Sonatas and interludes, compuestas entre 1946 y $1948^{1}$, ciclo de dieciséis sonatas y cuatro interludios, explora, retomando la filosofía india, el sabor, jugo o esencia estética (rasa) de una obra artística proyectada en el sentimiento o emoción (movimiento) que se experimenta en su acción performática. He aquí lo que planteaba Marcel Duchamp (1887-1968) cuando sostenía que una obra de arte solo la hace quien la contempla, pues el significado de un signo lo hace quien lo percibe como un trabajo de desciframiento de un código. La obra existe, tiene su materialidad, pero solo se hace obra en la confluencia de flujos de mediación intersubjetiva. El código se desplaza en el complejo de fuerzas de la máquina abstracta de la mirada comprensiva del intérprete, lo cual ya se presenta como una gran descodificación de los códigos en la pintura del siglo XV en el desciframiento de una secuencia de signos:

Pueden escuchar este ciclo de veinte piezas para piano de John Cage (2015) en el siguiente enlace: https:// www. youtube.com/watch?v=26K9f8n6ymU 
De un golpe vemos el derrumbamiento de la jerarquía de los sobrecódigos y de los códigos territoriales. Los flujos de pintura devienen locos, pasa un flujo estallando todos los códigos. Los pintores hacen cristos completamente "maricas", completamente amanerados. Todo está sexuado. Hacen vírgenes que equivalen a cualquier mujer, pequeños niños que vienen de beber, niños que hacen caca. Verdaderamente juegan esta operación de descodificación de los flujos de colores. (Deleuze, 2005, pp. 46-47)

El flujo palpa el vínculo con la obra en contraflujos que hacen emerger la experiencia estética en un sistema de ecos, repeticiones, oposiciones y simetrías que se pliegan como rasa (sabor) en una "maquina conjuntiva, pues se trata de poner en conjunción flujos de colores y de trazos descodificados" (Deleuze, 2005, p. 48). Ponerle rostro a este estremecimiento del código, en términos de una máquina conjuntiva, visual, se incarna en la obra de Tulio Restrepo, quien juega con los flujos de las cuatro edades del grafismo (Costa y Raposo, 2008):

- Primer flujo: el signo (-100.000 años)

- Segundo flujo: la imagen (-30.000 años)

- Tercer flujo: la escritura (-5.500 años)

- Cuarto flujo: el alfabeto (-3.000 años)

Estos cuatro flujos, sonatas de sabor estético, confluyen en un stimmung como emoción material en el grafismo de la mirada y en el espacio de percepción del sentido. El campo de inmanencia entre signo-imagen-escritura-alfabeto tiene su lugar (locus) de enunciación en la aspiración cubista, futurista, dadaísta, letrista, suprematista y $D e$ Stijl de encontrar una descodificación de los flujos en el poder sensible de un arte háptico en el juego de un caligrama de superficies parlantes, o en la que expresa Tulio Restrepo (2019), una vispoiesis: poemas visuales en las posibles simbiosis, metamorfosis o interacciones entre palabra e imagen. Las seis obras seleccionadas para la revista exponen el flujo del grafismo en la cinesis del signo-imagen-escritura-alfabeto del mensaje en la carne expresiva del intérprete, que también es un flujo en aquella poesía visual en el lenguaje estético de Tulio Restrepo.

Hunger the big misery (2013) expone una crítica, desde el empaque de unas "papitas McDonald's", de aquello que podría ser entendido como la envoltura sociocognitiva de una farsa motivada por un deseo de alimentarse sin medida, olvidando que se come en un acontecer de placer estético gustativo. La sociedad en la que vivimos es esa envoltura que hace del consumo el vínculo de compra ante un otro que es proyección de sí mismo cuando se trata de pagar. ¿Solo se es sujeto en el religare que nos une a la antropofagia consumista? Por ello, una economía libidinal en turbulencia consumista que 
ha devenido en aquello que ha sido llamado Antropoceno, momento histórico ligado al desarrollo del capitalismo, analizado en una de las traducciones que integran este número de la revista. He aquí una imagen aprisionada por su poder crítico en la distribución del grafismo de las marcas que circulan como postales en una sociedad de consumo antropófaga, lo cual queda propuesto en Carta en blanco (2008), pieza gráfica de un fondo negro que es interpuesto por un flujo óptico que nos lleva a la máquina conjuntiva mencionada atrás. Las letras en blanco exponen la críptica intención de una cadena comunicativa que solo es puesta en obra en un intérprete, otro contraflujo, que descodifica el código en un mensaje ligado a la archiescritura (la reiteración de una huella como acontecimiento interpretado). Así, se constituye uno sólo el esquema que une la forma con toda sustancia, gráfica o de otro tipo, sino el movimiento del signo-función, que vincula un contenido con una expresión, sea o no gráfica» (Derrida, 1971, p. 78).

En Sellos de caucho de artista correo (s.f.) y De lado (1990), Tulio Restrepo vuelve al fluxus de una realidad inmediata en el pathos de la huella del arte, donde lo cotidiano se imbrica en la íntima emoción de la experiencia estética (Tatarkiewicz, 2015). Por último, en las obras Arte poema postal. El amor en sus manos (1990) y Desaparecido (1999) se percibe la experiencia como una archihuella, no en un plano trascendental como la metafísica occidental ha hecho de la noción de experiencia, sino una contorsión inmanente al lenguaje en términos de una inscripción material en el encuentro incorporal de una materialidad sensible entre cuerpos. La huella sería la evidencia de ese encuentro (una mano que en los surcos de su piel encuentra al otro y una carta que desaparece al no tener contacto con su destinatario en la pura fragilidad del mensaje). Por ello, la síntesis que hace pensar las seis obras de Tulio Restrepo: "Esta huella es la apertura de la primera exterioridad en general, el vínculo enigmático del viviente con su otro y de un adentro con un afuera: el espaciamiento" (Derrida, 1971, p. 92). La huella solo aparece en el grama y en la diferencia como temporalización en el juego con el mensaje que es transportado por una redistribución de los materiales que el artista imprime en su obra. Agradecemos a Tulio Restrepo por permitirnos participar como intérpretes de las seis obras que integran este número de la revista, donde la cosa más familiar del mundo, la familiaridad en sí misma, permite al flujo convertirse en una huella que solo se descifra en la corporalidad de sus efectos y en el diferencial intersubjetivo de sus destellos de aparición estética (Benjamin, 2005).

Para terminar esta reseña, evoco un pasaje de El proceso de Kafka, que Walter Benjamin (2005) retoma para mostrar que la "modernidad" es "lo nuevo en el contexto de lo que ya siempre ha estado ahí" (p. 558), es decir, lo novísimo que permanece siempre siendo lo mismo en la eternidad del infierno de lo sombrío, 
visto, en la contemplación de una provocación estética, en un paisaje de landas que es archihuella en la materialidad que nos afecta:

"Solo un minuto más. ¿No quiere ver algún cuadro que yo pudiera venderle?". K. no quiso ser descortés, el pintor se había ocupado realmente de él y había prometido seguir ayudándolo; además, por distracción de K. no se había hablado en absoluto de la remuneración de su ayuda, por lo que K. no podía negarse ahora y dejó que le enseñara el cuadro, aunque temblaba de impaciencia por salir del estudio. El pintor sacó de debajo de la cama un montón de cuadros sin enmarcar, tan cubiertos de polvo que, cuando el pintor trató de soplarlo del cuadro de arriba, permaneció largo tiempo revoloteando ante sus ojos, asfixiante. "Un paisaje de landas", dijo el pintor, tendiendo a K. el cuadro. Representaba dos árboles frágiles que, muy alejados entre sí, se alzaban en la hierba oscura. Al fondo se veía una puesta de sol multicolor. "Muy bien", dijo K., "lo compro". Sin pensarlo se había expresado demasiado concisamente, y por eso se alegró que el pintor, en lugar de tomárselo a mal, levantara del suelo otro cuadro. "Aquí está la pareja de ese cuadro", dijo el pintor. Podía haber sido concebido como pareja, pero no se podía observar la menor diferencia con respecto al primero: allí estaban las flores, allí la hierba y allí la puesta de sol. Pero a K. no le importaba. "Son dos bonitos paisajes". Dijo, "los compro los dos y los colgaré en mi oficina". "El motivo parece gustarle", dijo el pintor, sacando un tercer cuadro. "Es una suerte que tenga todavía otro cuadro parecido". Pero no era parecido, más bien era exactamente el mismo paisaje de landas. (Kafka, 2012, pp. 154-156)

Lo que siempre ha estado allí es el eterno retorno de lo que se asoma como fogonazo en el grafema del instante percibido. Por ello, las seis obras de Tulio Restrepo, ofrendadas ante nuestra mirada, recuerdan la experiencia de lo que hemos vivido.

\section{Obras seleccionadas de Tulio Restrepo}

\section{Imagen 1}

\section{Título: Hunger the Big Misery}

Técnica: Postal reciclada (adhesivo, impresión de sello de caucho, gráfica digital sobre empaque comercial intervenido)

Dimensiones: $13 \times 14 \mathrm{~cm}$.

Año: 2013

\section{Imagen 2}

Título: Arte poema postal. El amor en sus manos

Técnica: Fotocopia intervenida con collage, impresión de sello de caucho sobre papel carta

Dimensiones: $21,59 \times 27,94 \mathrm{~cm}$.

Año: 1990 


\section{Imagen 3}

Título: Carta en blanco

Técnica: Gráfica digital

Dimensiones: 21,59 x 27,94 cm.

Año: 2008

\section{Imagen 4}

Título: Sellos de caucho de artista correo

Técnica: impresión de sellos de caucho

Dimensiones: variables

Años: 2012-2019

\section{Imagen 5}

Título: De lado

Técnica: Collage sobre empaque comercial intervenido

Dimensiones: variables: $21,59 \times 27,94 \mathrm{~cm}$.

Año: 1990

\section{Imagen 6}

Título: Desaparecido

Técnica: Collage, impresión de sellos de caucho, gráfica digital

Dimensiones: variables: $21,59 \times 27,94 \mathrm{~cm}$.

Año: 1999

\section{Referencias}

Benjamin. W. (2005). El libro de los pasajes. Ediciones Akal.

Cage J. (2015, 3 abril). 2015 Sonatas and interludes [video]. YouTube. https://www.youtube.com/ watch?v $=26 \mathrm{~K} 9 \mathrm{f} 8 \mathrm{n} 6 \mathrm{ymU}$

Costa, J. y Raposo, D. (2008). La rebelión de los signos. El alma de la letra. La Crjía.

Deleuze, G. (2005). Derrames entre capitalismo y esquizofrenia. Cactus.

Derrida, J. (1971). De la gramatología. Siglo XXI Editores.

Kafka, F. (2012). El proceso. Random House Mondadori.

Restrepo, T. (2019). Vispoiesis. Babilonia.

Tatarkiewicz, W. (2015). Historia de seis ideas. Arte, belleza, forma, creatividad, mímesis, experiencia estética. Editorial Tecnos. 